is $90-95 \% .^{2}$ Short term complications include back and neck ache, transient fever, and radicular pain; serious long term problems seem to be rare. ${ }^{3}$

Subdural haematoma is a rare but potentially fatal complication of dural puncture. ${ }^{34}$ It is probably caused by traction on the meninges inducing tearing of dural vessels. It is unclear whether bleeding occurs at the time of dural puncture or later as a result of persistent leakage of cerebrospinal fluid. Although there was no evidence of appreciable fresh bleeding at operation or on computed tomography in our patient, the time between dural puncture and evacuation of the haematoma (seven weeks) would have allowed a late haematoma to acquire an elderly appearance. The clear postural nature of the initial headache, and the change in symptoms a few days before the patient's final presentation, suggests that it was a relatively late event and might have been prevented by early epidural blood patching. There is little doubt that earlier aggressive investigation and treatment would have avoided the final, potentially life threatening episode of intracerebral decompensation.

This case raises several points. Ward staff should be alerted to the possibility of a headache after epidural or spinal anaesthesia, and patients should be seen by an anaesthetist before discharge. However, early dis- charge after vaginal delivery or minor surgery means that postdural puncture headaches may not evolve while the patient is in hospital. Patients receiving spinal or epidural anaesthesia should therefore be warned of the possibility of headache and be given clear instructions to refer back to an appropriate medical practitioner in the hospital should any problems occur. In addition, general practitioners and non-anaesthetic hospital medical staff should be aware of the importance of headache after dural puncture. Finally, the differential diagnosis of headache following dural puncture should include subdural haematoma, particularly if it does not improve after blood patching or if the clinical features are atypical.

We thank Mr D Price, consultant neurosurgeon, for permission to report this case.

1 Reid JA, Thorburn J. Headache after spinal anaesthesia. Br f Anaesth 1991;67:674-7.

2 Abouleish E, de la Vega S, Blendinger I, Trio T. Long term follow up of epidural blood patch. Anesth Analg 1975;54:459-63.

3 Edelman JD, Wingard DW. Subdural hematomas after lumbar puncture. Anesthesiology 1980;52:166-7.

4 Newrick P, Read D. Subdural haematoma as a complication of spinal anaesthetic. $B M F$ 1982;285:341-2.

(Accepted 20 January 1993)

\title{
Old people's homes: the relatives' view
}

\author{
Mavis Nicholson, Dorothy White
}

On 1 April new arrangements came into force for arranging and funding residential care for elderly people in Britain. From now on those who seem to need full time care will be assessed first by care managers employed by local authority social services departments. This may lead to admission to an old people's home or a nursing home.

Local authorities have been told to consult both users and carers about such decisions. But what about relatives who have not actually been giving care directly?

The Relatives Association was set up last year as a voluntary organisation for the relatives and friends of older people living in residential homes. Below, its vice president, Mavis Nicholson, a journalist and broadcaster whose mother died of Alzheimer's disease in a residential home last year, gives her personal view of being such a relative. And Dorothy White, the association's founder, explains what the future may hold for elderly residents and their relatives.

\section{A home for mother}

Moving someone you love from your home into a Home can never be anything less than upsetting. It is a big decision even when it is a necessary one. For some people it is traumatic, however much they tell themselves it is for the best.

My sister and I were racked with guilt-brain washed, I think, by past notions of old people's homes. They were little better than workhouses, parish run, where unloved nuisances were abandoned. Only heartless children put their parents into them to exist, neglected, until they died. We should surely have got rid of such hang ups by now. But many 60 year olds like myself still have to fight down these very real imaginings.

I sincerely hope my children will not have to fight them when my time comes. I'll leave them a letter of permission, for one thing, taking the onus off them. And, for another, I hope to put my name down for a good home while I'm still capable of making the choice. Ideally I would like to do some voluntary work in the one I have my eye on, so that I'd feel at home there even before I took up residence.

The search for the right home for my mother was gruelling. My sister did most of the groundwork, working on gut reaction, but she found she had little choice. The home we eventually settled on was in fact the only one we could feel positive about. It did not smell of urine, was nicely furnished like a family hotel, and was run by people who seemed naturally affectionate.

But then we came up against some snags in ourselves. My sister was absolutely exhausted from looking after our mother. I felt bad because I hadn't done much of that and here was I about to do even less.

The worst thing about putting your relative in a home is suddenly seeing the person you love in a communal sitting room with all the others who are just like her. On her own, in my sister's house, my mother hadn't seemed pathetic. The privacy had given her some dignity. Now the multiplication struck me as ludicrous, and she was diminished and exposed by it. It had nothing to do with the home itself. I had to make myself get over this reaction. This was life.

\section{SHOCKS FOR RELATIVES}

Another terrible shock came when I arrived to find my mother wearing something that didn't belong to her. I wasn't alone in this. I remember seeing a staid 


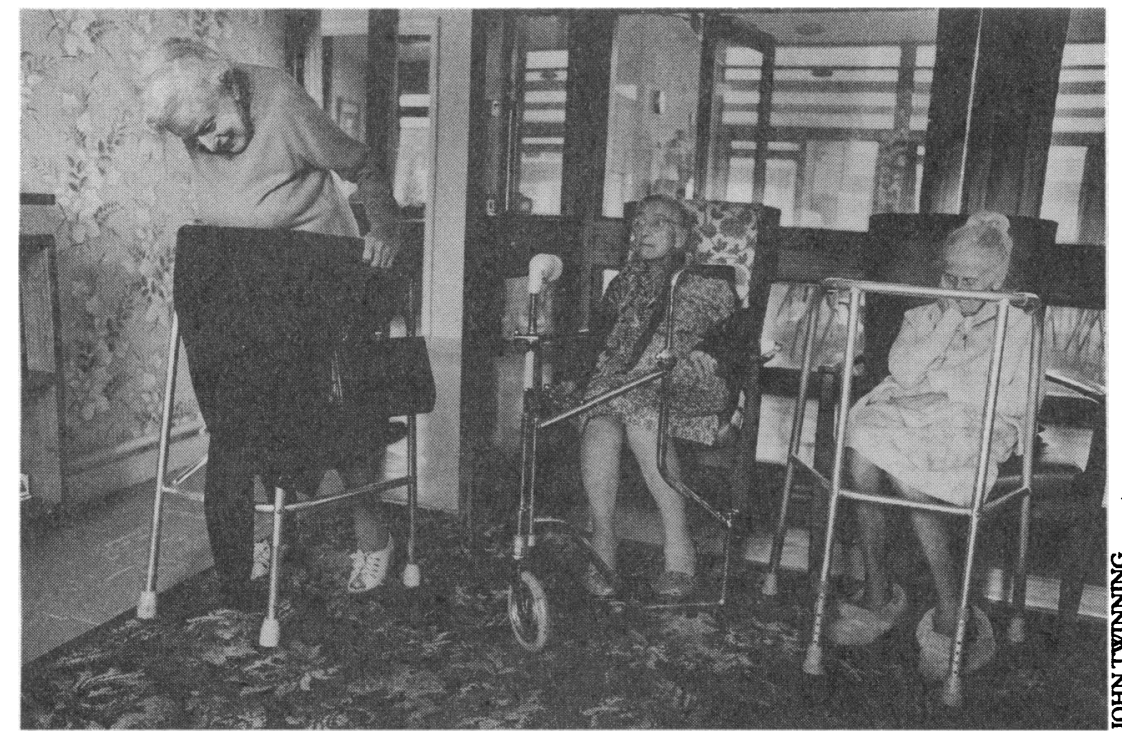

Care in a residential home is ofien the best solution for a problem with no ideal solutions

old gent, whom I'd got to know, appear one afternoon in bright turquoise trousers. And just as I was thinking that with his wits about him he would have died rather than be seen in them, his sister walked in and nearly had forty fits.

As a visitor to an old people's home you already feel bewildered-slightly lost in trying to keep your relationship going with someone who has, in a sense, been taken over by other people. But to see them dressed out of character is too much. Staff can't know exactly how their residents used to dress. So they really should ask relatives to tell them. Labelling clothes and sticking to them is an obvious answer.

One Easter the staff at the home bought everyone a new cardigan for the holiday-a nice gesture. But my mother's was a colour she would never have chosen in a million years and it clashed with all her own clothes.

It is easy to feel you have lost any relative who goes into a residential home, anyway. You can hardly ever do anything for them. Keeping up a conversation is dire. No wonder other members of the family stop visiting them. They feel spare.

And they feel more guilt. You have failed to look after this lost person to the very end, especially in the case of a mother, who had looked after you from the beginning.

BUILDING BRIDGES, MAKING CHANGES

The ordeal is worse for people who, like my sister, have been full time carers. She says she didn't know what hit her when our mother went into the home. She felt isolated. The purpose in her life (even though it had been wearing her out) had gone. Previously her days had been filled with the bath nurse arriving, Meals on Wheels sometimes, the ambulance driver taking mother to the day centre, the day centre staff when she picked up my mother. Then, overnight, everything changed. No visitors arrived. And when she went to the home to see her mother, there was nothing for her to do, although she used to do everything.

There are not anything like enough bridges between those who run homes and those who visit. Similarly, before parent teacher associations were formed, there were no links in schools between teachers and parents. Old people's homes could learn from their lesson.

One of the first things relatives could change is the baby talk in which staff speak to residents. It maybe that staff use this language because they are young and fresh from talking to their own babies like this. Or maybe it's because they are setting up a barrier between themselves and the sorry plight of the people they are caring for day by day.
It is well intended, I'm pretty sure. But I saw it baffling my mother. She looked around to see which infant or puppy they were addressing. She'd answer very primly at first, as if to ward it off.

I worried that it hastened her surrender to being a helpless little thing. But old age is not, in my view, a second childhood. My mother's Alzheimer's disease took away her ability to think who she was, but she was still Olive Irene Mainwaring, an adult who had been a bright and thinking woman in her day.

\section{The Relatives Association}

The Relatives Association was set up last year to give the relatives and friends of elderly people in residential care and nursing homes a chance to voice their views on the care given. Many relatives have feelings of isolation, guilt, and frustration which they do not know how to channel. Yet relatives are often able to make sure that care in a residential home is of really good quality and that the individuality of elderly residents is understood and maintained. Many want to do more to help and want to be more aware of the way in which residential homes are run.

Many relatives find that staff are always under pressure, are not well paid, and have very little training. Most relatives are grateful for the concern and kindness shown by the staff. Some worry that they are entrusting their elderly people to a system in which the circumstances of managing homes seem to work against providing the quality and individuality of care they hope for. Yet the fees for residential care often seem enormous and way beyond the limits now covered for residents by income support.

Elderly residents are usually much too frail to be active consumers, but their relatives can take up these issues on their behalf. With this in mind, the Relatives Association was founded. Its main aims are

- to provide an organisation through which relatives can work together with residential homes to maintain and improve the quality of care for older people;

- to provide advice and support to relatives;

- to help develop local groups or networks of relatives; - to provide a voice for relatives, both locally and nationally.

THE FIRST YEAR

During the first year the bulk of the association's work has been to provide an advice and information service. Much of this is done through listening to relatives who telephone for help. It has been possible to help people reconcile themselves to their own feelings of guilt and to talk through their worries about the care of their elderly relatives. Often they find it difficult to take things up with homes. The association helps relatives to sort out what they would like to see changed and gives them the understanding and backing to discuss this with the home's staff.

Most relatives contacting the association do not seem to want to make a formal complaint-although sometimes this may be necessary. They recognise that a home is a living community and that all those concerned-the residents, the staff, the management, and the relatives-have to work together. But more than anything, the relatives want to cease being mere visitors, always on the outside. They want to be brought into the inside.

By responding to consultation documents from the Department of Health, through publications and conferences, and through discussion with owners of residential homes, the association has tried to create a climate of understanding not only of the importance of the continued involvement of their families when older people go into homes, but also of the value of making sure they are able to express their views about the many 


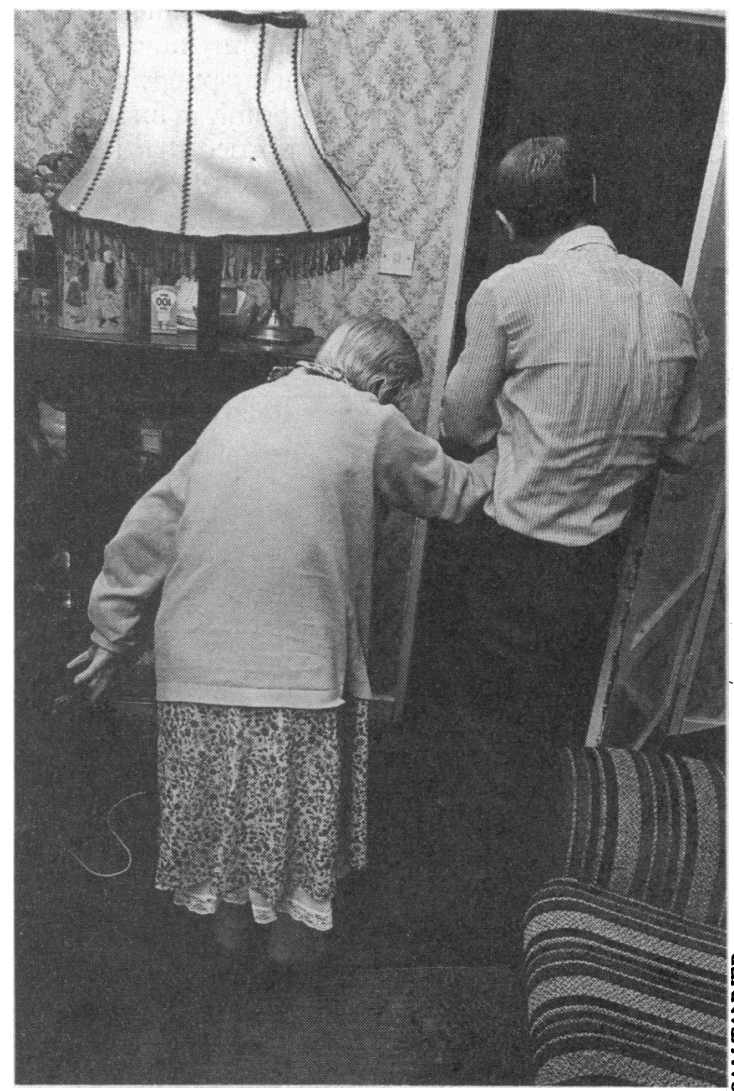

Some elderly people are too frail to be active consumers

issues surrounding the provision of care in homes. Relatives may no longer be direct carers (and, indeed, some may never have been carers before the residents went into the homes), but they are usually deeply concerned and are usually the most frequent visitors in homes. They can and do observe what goes on, but they are seldom consulted.

During its first year the association has conducted a pilot study of what relatives thought were the good and not so good features of residential homes and of their views about residents' reactions to being in homes. ${ }^{1}$ We are now working on three booklets which will help relatives to understand better the basic principles and aims in running a home, and which will help both relatives and homes in difficult task of building up groups of relatives and friends (analogous to schools' parent teacher associations) to work constructively with the home and its staff.

The next task is to help the formation of these groups and of local support networks of relatives. The association does not necessarily intend to start local branches unless this is what local people want; the aim is to get discussion going with local authorities, associations of residential home owners, councils for voluntary service, and local branches of voluntary organisations such as Age Concern, Carers National, and the Alzheimer's Disease Society.

\section{THE COMMUNITY CARE REFORMS}

How does all this fit in with the new arrangements for community care? We hope that the reforms will provide additional flexibility which will help elderly people to remain in their own homes if this is what they want. Our small pilot study of 65 relatives showed that elderly people tend to feel that being in a residential home is at best a necessary decision.'

But full time care at home, if that has to imprison a member of the family for several years, may not be a good solution either. Elderly people needing full time care are usually 85 or older and their children are usually in their late 50 s and 60 s. Half a century ago the ratio of 50-60 year olds to those over 85 was 14:1; now the proportion is $5: 1$. This is a profound change which puts the pressure of family caring on very few people. This pressure could be increased by a climate of opinion that expects 50-70 year olds to take on the full time care of their aging parents.

\section{FAMILY DYNAMICS}

Husbands and wives will probably want to go on looking after each other for as long as they possibly can, but the situation may be different for children. The offspring of very elderly people may not be in the best of health, nor may their spouses. They often have other family responsibilities. And some may want some time to lead their own lives before old age overtakes them or to make their contributions to society in different ways from undertaking the full time care of a parent. Finally, there are very real problems when families have never got on well with each other at close quarters. This is why, for many frail elderly residents and their families, care in a home has seemed the best solution for a problem for which there are no ideal solutions.

There are national economic factors that worry relatives too. Gradually, because income support is given within strict limits, relatives have been pushed into contributing to fees when the residents have used up all their own money. Many relatives can no longer rely on a trickle down of inheritance; they have to contribute from their own resources. It remains to be seen whether this will still happen in the future for residents whose places are purchased by local authorities.

\section{ISSUES FOR THE FUTURE}

The issue for the future which very much concerns the association is the need to recognise that care in residential homes must still be a part of community care for elderly people who can no longer remain in their own homes. There may be different ways of providing residential care: through smaller units; through arrangements in which relatives and friends do some of the caring; and through closer links with day services so that very old people can attend residential homes regularly before becoming residents. Two major issues are the best way to look after people with Alzheimer's disease and the division between residential care and nursing homes.

The relatives of those in residential homes not only have a great deal to contribute to maintaining present standards of care; many have insights to offer about the future. They should be involved in planning and monitoring, not only for their parents or spouses or friends now, but for their own sakes in the future. One of the tasks of the Relatives Association is to ensure that they are able to make that contribution.

The association was fortunate in starting its life within the auspices of Counsel and Care, a major charity working on behalf of older people. This helped in the initial applications for care funding and provided a base. The association now has its own separate charity registration but will maintain links with Counsel and Care. It must, however, pay its way. The association now has a grant from the Department of Health to cover part of its costs and some charitable trust funding, but the greater part of the work of running the association and of developing locally must come through voluntary effort. Retired people who are used to organising things, and who are, or have been, "relatives" are urgently required to assist in this.

Those who are interested in finding out more about the association, or have help to offer, should write to the Relatives Association, Twyman House, 16 Bonny Street, London NW1 9PG, or telephone 0712842541 .

1 White DM. Relative views. London: Relatives Association, 1993 